\title{
LETTER
}

\section{ICU survival and the central to mixed venous oxygen difference}

\author{
Vinayak Jha* and Guillermo Gutierrez \\ See related research by van Beest et al., http://ccforum.com/content/14/6/R219
}

We read with interest the recent study on central venous saturation $\left(\mathrm{ScvO}_{2}\right)$ and mixed venous saturation $\left(\mathrm{SvO}_{2}\right)$ in 53 patients with severe sepsis [1]. For several reasons, however, we feel the authors' broadly stated conclusion that 'a positive $\left(\mathrm{ScvO}_{2}-\mathrm{SvO}_{2}\right)$ value is not associated with improved outcome' is unwarranted.

First, in Figure 3 of their paper, graphing the number of measurements rather than the number of subjects is counterintuitive; your readers may find the latter a more clinically useful metric. The meaning of the columns is obscure because a single subject can contribute measurements to both columns (less than and greater than zero).

Second, the total number of measurements depicted in each Figure 3 column is crucial information, but is not provided. After physically measuring the height of the columns, we estimate 278 total measurements, rather than 265 as noted in the text.

Third, we question how the $P$-value $(P=0.13)$ for a total population can be numerically equal to the lowest $P$-value of two constituent groups of similar size.

Finally, the authors should consider acknowledging the possibility of a type II error when stating their conclusion. Specifically, if the total number of measurements were doubled, keeping the proportions the same, the $P$-value would decrease to 0.08 (Chi square with Pearson's correlation). If tripled, then the $P$-value becomes $P<0.0001$.

We welcome new studies on survival and $\left(\mathrm{ScvO}_{2}-\mathrm{SvO}_{2}\right)$ difference, and do not believe the current study casts doubt on our finding [2] that a positive difference is strongly associated with survival.

\section{Authors' response}

Paul A van Beest, Jan van Ingen, E Christiaan Boerma, Nicole D Holman, Henk Groen, Matty Koopmans, Peter E Spronk and Michael A Kuiper

We thank Dr Jha and Dr Gutierrez for their interest in our study. Our main conclusion was that $\mathrm{ScvO}_{2}$ does not reliably predict $\mathrm{SvO}_{2}$ (or vice versa) in patients with severe sepsis [1]. We consider this important as $\mathrm{ScvO}_{2}$ and $\mathrm{SvO}_{2}$ are sometimes used interchangeably as substitutes of each other. We think that this is a practice for which there is no evidence, and we provided proof against this practice.

The use of measurements rather than subjects may appear counterintuitive, but reflects the clinical reality when one looks for a positive $\left(\mathrm{ScvO}_{2}-\mathrm{SvO}_{2}\right)$ value in patients.

We understand that it may seem strange that the $P$-value for the association between survivorship and

*Correspondence: vjha@mfa.gwu.edu

The George Washington University Medical Faculty Associates, Division of Pulmonary, Critical Care, and Sleep Medicine, 2150 Pennsylvania Ave NW, Suite 5-425, Washington DC 20037, USA
$\left(\mathrm{ScvO}_{2}-\mathrm{SvO}_{2}\right)$ is the same for the total population and for the non-splanchnic subgroup $(P=0.13)$, while the $P$-value for the splanchnic subgroup is higher $(P=0.23)$. However, the relationship is in the same direction in both subgroups, although slightly different in strength (Figure 3 in [1]) with the strongest association in the nonsplanchnic group. Therefore, when the two subgroups are combined, the overall association will be weaker than in the non-splanchnic group, but due to the bigger sample, the $P$-value may be the same as in the subgroup of nonsplanchnic sepsis patients. The number of paired measurements is 265, as was stated in the text.

And finally, we do acknowledge the possibility of a type II error. We agree with the statement of the authors [2] that whether therapy aimed at increasing a positive $\left(\mathrm{ScvO}_{2}-\mathrm{SvO}_{2}\right)$ value results in improved ICU survival remains to be determined.

\section{Abbreviations}

$\mathrm{ScvO}_{2^{\prime}}$ central venous saturation; $\mathrm{SvO}_{2}$, mixed venous saturation.

Competing interests

The authors declare that they have no competing interests. 


\section{Published: 30 June 2011}

\section{References}

1. van Beest PA, van Ingen J, Boerma EC, Holman ND, Groen H, Koopmans M, Spronk PE, Kuiper MA: No agreement of mixed venous and central venous saturation in sepsis, independent of sepsis origin. Crit Care 2010, 14:R219.

2. Gutierrez G, Comignani P, Huespe L, Hurtado FJ, Dubin A, Jha V, Arzani Y, Lazzeri S, Sosa L, Riva J, Kohn W, Suarez D, Lacuesta G, Olmos D, Mizdraji C,
Ojeda A: Central venous to mixed venous blood oxygen and lactate gradients are associated with outcome in critically ill patients. Intensive Care Med 2008, 34:1662-1668

doi:10.1186/cc10260

Cite this article as: Jha V, Gutierrez G: ICU survival and the central to mixed venous oxygen difference. Critical Care 2011, 15:436. 